Rev. Interd. em Cult. e Soc. (RICS), São Luís, v. 7, n. 1, p. 28- 43, jan./jun. 2021

ISSN eletrônico: 2447-6498

\title{
Pesquisa Artística: um breve panorama ${ }^{1}$
}

\author{
Artistic Research: a brief review
}

\author{
DANIEL LEMOS CERQUEIRA \\ Professor do Departamento de Música \\ da Universidade Federal do Maranhão (UFMA) \\ Conteudista do curso de Música Licenciatura a distância da \\ Universidade Estadual do Maranhão (UEMA) \\ daniel.lemos@ufma.br
}

\section{RESUMO}

Artigo sobre a pesquisa artística como método de investigação no meio acadêmico. Parte-se de um panorama internacional com pesquisadores destacados no tema, sucedido de um breve retrospecto histórico sobre a natureza do método científico na academia. Apresenta-se em seguida o conceito de pesquisa artística e as dualidades pesquisa sobre artes e pesquisa através das artes, bem como conceitos associados ao tema. Conclusões apontam para uma longa trajetória até o estabelecimento da pesquisa artística no meio acadêmico.

Palavras-chave: Arte. Metodologia da pesquisa. Pesquisa artística. Método científico. Interdisciplinaridade.

\begin{abstract}
This work aims to study briefly artistic research on the academy. There is a presentation regarding the international scenario on the subject, along with outlined researchers, followed by a short historical description of the scientific method on the academy along with its establishment. In follow, there is an explanation regarding the concept of artistic research and its two divisions - research on the arts and research in the arts - with some relevant concepts related to the topic. Conclusions point to an extense path until the establishment of artistic research on the academic world.
\end{abstract}

Keywords: Art. Research Methodology. Artistic Research. Scientific Method. Interdisciplinary.

\section{CONTEXTUALIZAÇÃO}

Nas três últimas décadas, o meio acadêmico internacional tem presenciado a emergência do debate sobre a pesquisa artística, mesmo que de maneira desigual entre países. Ao estabelecer um panorama acerca do tema, o musicólogo holandês Henk Borgdorff - autor de estudos centrais sobre o assunto -, aponta notáveis conquistas na Áustria, Holanda, Noruega, Finlândia, Reino Unido, Bélgica, Alemanha, Suíça e Austrália (BORGDORFF,

\footnotetext{
${ }^{1}$ Artigo submetido para avaliação em 25/04/2021 e aprovado em 01/05/2021.
} 
Rev. Interd. em Cult. e Soc. (RICS), São Luís, v. 7, n. 1, p. 28- 43, jan./jun. 2021 ISSN eletrônico: 2447-6498

2012). A coreógrafa sueca Efva Lilja acrescenta França, Croácia e Romênia (LILJA, 2015), enquanto o musicólogo espanhol Rúben López-Cano e a musicista-pesquisadora Úrsula San Cristóbal Opazo incluem a Espanha e, na América Latina, Colômbia e México (LÓPEZCANO; SAN CRISTÓBAL OPAZO, 2014). Os avanços mencionados pelos autores, em ordem ascendente de estabelecimento, são:

- Criação e manutenção de fóruns de discussão para artistas envolvidos com a pesquisa acadêmica;

- Flexibilização institucional de formulários, regimentos e procedimentos de investigação para viabilizar e abarcar as necessidades da pesquisa artística;

- Realização de congressos, simpósios e similares direcionados à pesquisa artística;

- Estabelecimento de uma biblioteca ou base de dados virtual e multimídia para publicação e divulgação dos estudos resultantes de pesquisas artísticas;

- Fundação de cursos de Doutorado com foco na realização de pesquisas que possuem a prática artística como método de investigação, em status igualitário aos cursos baseados em abordagens já estabelecidas no meio acadêmico;

- Financiamento específico das agências de fomento para a produção da pesquisa artística;

- Menção às Artes e à pesquisa artística em documentos governamentais como meios de produção do conhecimento em paridade com as Ciências.

Segundo os autores mencionados, ainda são poucos os países em que tais ações foram implementadas. O meio acadêmico é conservador, portanto, há resistência acerca das reformulações que o debate sobre a pesquisa artística proporciona e, especialmente, do ponto de vista conceitual. Borgdorff ilustra os perfis que comumente rejeitam o tema:

Para alguns artistas, a requisição de fazer um pouco mais para articular sua
investigação é vista como uma imposição não garantida em sua prática. Para
certos acadêmicos já estabelecidos no campo das Artes, a prática como
pesquisa não é uma metodologia respeitável, podendo ser vista como uma
nódoa em subdisciplinas de Arte e Mídia recém-consolidadas. Para alguns
acadêmicos de disciplinas não artísticas que dispõem de metodologias
estabelecidas e métodos quantitativos e qualitativos, a prática como pesquisa
é um desafio sobre pressupostos fundamentais acerca do que se entende por
'pesquisa' e 'conhecimento', além do risco de aumentar a competição pelo já
escasso fomento à pesquisa. (BORGDORFF, 2012, p. 4)

Esta breve citação já apresenta um dos pontos mais sensíveis do debate: o que se entende no meio acadêmico por "conhecimento", "pesquisa" e, consequentemente, "Ciência"? Como as Artes se situam (ou melhor, se adéquam) junto aos conceitos, metodologias, regras e 
Rev. Interd. em Cult. e Soc. (RICS), São Luís, v. 7, n. 1, p. 28- 43, jan./jun. 2021

ISSN eletrônico: 2447-6498

formulários já estabelecidos para o que se define como "Ciência"? E qual a necessidade de manter a distinção entre Arte e Ciência nesse contexto? O pianista italiano Luca Chiantore acrescenta outro questionamento:

\begin{abstract}
A pesquisa produz conhecimento. Mas que tipo de conhecimento a pesquisa artística busca? Não seria a arte por si mesma produto de uma investigação? Há sentido tratar da 'pesquisa artística' sob um âmbito específico, ou é preferível não associar a arte com um tipo de conhecimento que, tradicionalmente, deve ser racional e verbalizável para assim ser incluído no mundo acadêmico? (CHIANTORE, 2014 apud LÓPEZ-CANO; SAN CRISTÓBAL OPAZO, 2014, p. 10)
\end{abstract}

A partir da inquietação que estas perguntas proporcionam, iremos abordar o conceito de pesquisa artística a partir de um sucinto retrospecto histórico acerca do meio acadêmico e as definições que constituem seus pilares de sustentação.

\title{
2 TRAJETÓRIA DO MÉTODO CIENTÍFICO NO MEIO ACADÊMICO
}

O embrião do que se entende tradicionalmente por "pesquisa" e "Ciência", no meio acadêmico "Ocidental", , remonta ao século XVI. Nesse momento, o Renascimento - um movimento essencialmente artístico-cultural -, afrontava os preceitos "obscuros" da Idade Média, como o teocentrismo. Isaac Newton, Galileu Galilei, Francis Bacon e René Descartes definem os fundamentos do método científico, priorizando o conhecimento lógico-racional sobre o chamado "senso comum":

A forma mais usual que o homem utiliza para interpretar a si mesmo, o seu mundo e o universo como um todo, produzindo interpretações significativas, isto é, conhecimento, é a do senso comum, também chamado de conhecimento ordinário, comum ou empírico. (KÖCHE, 2011, p. 23)

Estes cientistas tinham como objeto de suas pesquisas os fenômenos da natureza. Assim, até os dias atuais, os métodos de investigação característicos das Ciências Exatas e da Natureza - campo sobre o qual o meio acadêmico construiu todo seu alicerce filosófico, metodológico e institucional -, trazem consigo os fundamentos destes autores.

Ao tratar das titulações, Borgdorff afirma que até o século XIX, apenas três

\footnotetext{
${ }^{2}$ Vamos utilizar a palavra "Ocidental" entre aspas por falta de uma denominação mais apropriada para se referir à herança cultural de origem europeia, uma vez que: a) este termo é conflituoso com sua denotação geográfica; b) existem diversas culturais não-europeias na região Ocidental do globo terrestre; e c) a própria cultura de natureza identitária europeia já não está mais restrita somente ao continente europeu.
} 
Rev. Interd. em Cult. e Soc. (RICS), São Luís, v. 7, n. 1, p. 28- 43, jan./jun. 2021 ISSN eletrônico: 2447-6498

especialidades emitiam títulos de doutor: Medicina, Ciências Jurídicas (Direito) e Teologia ${ }^{3}$. Havia neste contexto, portanto, uma hierarquia entre as áreas do conhecimento. Foi o filósofo alemão Immanuel Kant que, a partir de seus tratados, questionou o modelo vigente, propondo que quaisquer áreas pudessem oferecer doutoramentos e, assim, liberdade para a pesquisa. Tal fato se concretizou por meio da Universidade Friedrich Wilhelm de Berlim (atualmente Universidade Humboldt), em 1809 (BORGDORFF, 2012, p. 25).

Foi também no século XIX que os estudos sobre o pensamento humano - as Ciências Sociais e Humanidades -, foram reconhecidos no meio acadêmico e passaram a fazer parte dele. Este acontecimento foi iniciado com a revisitação aos pensadores da Grécia Antiga, e sua divisão dos tipos de conhecimento até hoje impactam o modus operandi da academia: episteme como conhecimento intelectual verdadeiro e techné como habilidade necessária para a concepção criativa (poiesis) e sua realização (práxis). Aqui, nasce a separação entre teoria e prática, juntamente com um julgamento de valores. Exemplo ilustrativo se dá na concepção de artista como artesão, cujo ofício é baseado em habilidades manuais: o "saber" seria mais importante que o "fazer", o qual, por sua vez, provém do "senso comum". E este último, já nos fundamentos que emergiram no século XVI, deveria ser refutado.

No século XX, as bases teóricas de diversas áreas do conhecimento passaram por reformulações sensíveis. Nas Ciências da Natureza, Albert Einstein desenvolveu a Teoria da Relatividade que, além de revolucionar as concepções da Física Newtoniana, não negou os modelos anteriores de Nicolau Copérnico e Cláudio Ptolomeu - cada um deles adotando como referência um observador diferente. Já as Ciências Sociais se estabeleceram por meio da consolidação de métodos científicos próprios, a exemplo das áreas de Sociologia, Antropologia, História e Psicologia. Nessa última, estudiosos como Jerome Bruner e Howard Gardner apresentam perspectivas diferentes em relação aos tipos de conhecimento considerados "válidos" no meio acadêmico, abrindo com estudos sobre a intuição (BRUNER, 1973) e diferentes tipos de habilidades advindos da Teoria das Inteligências Múltiplas (GARDNER, 2002). A etnografia, ferramenta de pesquisa originária da Antropologia, transita horizontalmente em diversas áreas do conhecimento, inclusive nas Artes. A oralidade passou a ter aceitação como forma de elaboração e preservação do conhecimento, especialmente na História. E nas Artes, o Modernismo trouxe valores significativamente distintos da estética em relação aos movimentos anteriores.

No entanto, ao abordar as perspectivas da metodologia científica em fins do século

\footnotetext{
${ }^{3}$ Daí provém o hábito de referência a graduados em Medicina, Direito e áreas afins como sendo "doutores".
} 
Rev. Interd. em Cult. e Soc. (RICS), São Luís, v. 7, n. 1, p. 28- 43, jan./jun. 2021

ISSN eletrônico: 2447-6498

XX, o sociólogo Boaventura Santos assim se posiciona:

Quando, ao procurarmos analisar a situação presente das ciências no seu conjunto, olhamos para o passado, a primeira imagem é talvez a de que os progressos científicos dos últimos trinta anos são de tal ordem dramáticos que os séculos que nos precederam - desde o século XVI, onde todos nós, cientistas modernos, nascemos, até ao próprio século XIX -, não são mais que uma pré-história longínqua. Mas se fecharmos os olhos e voltarmos a abrir, verificamos com surpresa que os grandes cientistas que estabeleceram e mapearam o campo teórico em que ainda hoje nos movemos viveram ou trabalharam entre o século XVIII e os primeiros vinte anos do século XX, de Adam Smith e Ricardo a Lavoisier e Darwin, de Marx e Durkheim a Max Weber e Pareto, de Humboldt e Planck a Poincaré e Einstein. E de tal modo é assim que é possível dizer que em termos científicos vivemos ainda no século XIX e que o século XX ainda não começou, nem talvez comece antes de terminar. (SANTOS, 2008, p. 13-14)

Nesta perspectiva, Santos defende que houve desenvolvimento limitado em relação ao método científico, uma vez que as concepções de "conhecimento" e "pesquisa" na academia continuam alicerçadas sob fundamentos mais que centenários. É aqui que a pesquisa artística possui potencial de contribuição.

\section{DEFININDO A PESQUISA ARTÍSTICA}

Lilja oferece uma compreensão direta sobre o que é pesquisa: "é simplesmente uma forma de ampliar o conhecimento e a percepção sobre o que desejamos saber" (LILJA, 2015, p. 15). Borgdorff reforça que "nas últimas décadas, uma liberalização gradual e notável tem ocorrido sobre o que se compreende por 'pesquisa' no mundo acadêmico" (BORGDORFF, 2012, p. 67). Já o musicólogo Renato Borges, ao tratar sobre a produção acadêmica da área de Música, é mais específico ao afirmar que "pesquisa" pode se referir tanto ao processo de investigação quanto ao produto resultante desse estudo (BORGES, 2019, p. 209-210). Tanto Lilja (2015) quanto Borgdorff (2012) destacam que a revisão por pares, presente no método científico, também é fundamental para o desenvolvimento das Artes, principalmente porque o autodidatismo é fortemente presente nesse campo e, com ele, a falta de diálogo gerada por uma postura individualista. Salientamos que não é possível oferecer contribuições significativas na produção do conhecimento sem referências, seja na Ciência ou na Arte. Assim como um cientista é capaz de situar uma produção em meio à literatura de sua área, o mesmo pode ser feito por um artista em relação à obra de arte, ao processo ou ao produto de um estudo. 
Rev. Interd. em Cult. e Soc. (RICS), São Luís, v. 7, n. 1, p. 28- 43, jan./jun. 2021 ISSN eletrônico: 2447-6498

A pesquisa artística pode ser definida como todas as pesquisas realizadas nas Artes e nas diversas áreas que a compõem - Literatura, Artes Visuais, Artes Cênicas, Música, Teatro, Cinema e Arquitetura, entre outras. Nessa perspectiva, o debate sobre a pesquisa artística no Brasil existe desde a década de 1980, quando o Conselho Nacional de Desenvolvimento Científico e Tecnológico (CNPq) decidiu por incluir as Artes em sua estrutura funcional inclusão que se deu por meio de debates acalorados, conforme aponta o artista e professor Silvio Zamboni, envolvido nas comissões do órgão na época (ZAMBONI, 2001). Dentre os desafios que ora se mostraram, além da busca por apoio ou ao menos compreensão dos acadêmicos de outras áreas do conhecimento, foi mais evidente a definição de critérios para mensuração e avaliação da produção acadêmica das Artes, nos casos de incompatibilidade com formulários e protocolos direcionados a áreas já estabelecidas. Contudo, Zamboni nota que há mais características em comum entre a Arte e a Ciência do que divergências:

Tanto a ciência quanto a arte, enquanto processos criativos e instrumentos do conhecimento humano, guardam semelhanças estreitas. Tanto em uma quanto noutra, é necessária a combinação dos aspectos racionais e intuitivos para se desenvolver os produtos gerados por suas atividades (ZAMBONI, 2001, p. 95-96).

Em relação aos métodos de investigação adotados na pesquisa artística, é interessante a classificação feita pelo historiador inglês Christopher Frayling e aprimorada por Borgdorff (2012). Ela deixa evidente as particularidades que a pesquisa artística possui em relação aos métodos científicos convencionais. Adiante, iremos apresentar uma proposta simplificada do modelo (Figura 1):

Figura 1. Modelo geral para a pesquisa acadêmica, ilustrando dois tipos de pesquisa artística

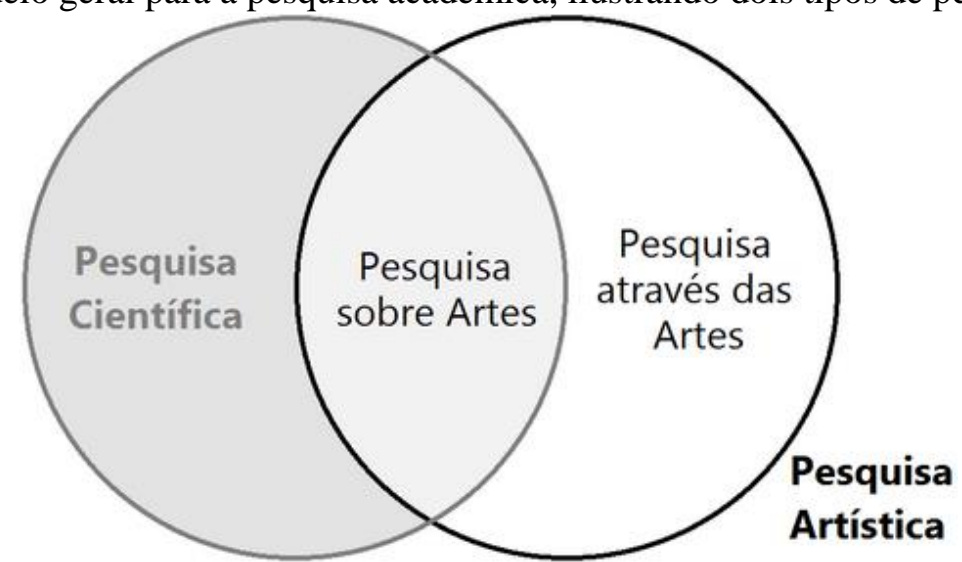

Fonte: Elaboração do autor, 2021. 
Rev. Interd. em Cult. e Soc. (RICS), São Luís, v. 7, n. 1, p. 28- 43, jan./jun. 2021 ISSN eletrônico: 2447-6498

Sob o conceito mais amplo de pesquisa artística, o modelo apresentado na Figura 1 apresenta duas classificações segundo os métodos utilizados nas investigações:

1) Pesquisa sobre Artes: são os estudos que têm como objeto produções (obras de arte) ou práticas artístico-culturais mediante uso exclusivo de métodos científicos já estabelecidos e tomados de empréstimo de outras áreas do conhecimento e que, por isso mesmo, também podem ser considerados pesquisa científica em um viés tradicional. Assumem abordagens quantitativas e qualitativas, além do que Borgdorff chama de "distanciamento teórico" entre pesquisador e objeto ${ }^{4}$. Os métodos que podem ser adotados são análise estatística, historiografia, entrevistas, questionários, observação e etnografia, entre outros. Os produtos finais desses estudos podem ser plenamente entendidos através de descrição textual e verbalização, podendo ser publicados através dos meios tradicionais de divulgação da produção científica: livros, capítulos, monografias, dissertações, teses, artigos, palestras, comunicações orais e mesas-redondas. Disciplinas características deste tipo de pesquisa artística são História da Arte, Filosofia da Arte, Sociologia da Arte, Estética, Antropologia Cultural e Musicologia, por exemplo. Nesta categoria, incluímos também o que Borgdorff chama de "pesquisa para as artes", voltadas a oferecer condições para que a produção artístico-cultural aconteça, como estudos sobre condições acústicas de espaços culturais e construção de equipamentos e instrumentos musicais, entre outros; estes tipos de pesquisa também fazem uso de métodos científicos importados de outras especialidades.

2) Pesquisa através das artes: são os estudos em que práticas artístico-culturais constam no método de investigação. Dessa forma, é preciso acessar conhecimentos não verbalizáveis e até mesmo não documentáveis como informações táteis, cinestésico-motoras, espaciais e imagens complexas de visão e audição, adquiridos a partir da experiência artístico-cultural do pesquisador - este é o conceito de conhecimento incorporado ${ }^{5}$ (BORGDORFF, 2012, p. 47). É comum que o processo da pesquisa seja mais relevante para a geração do conhecimento que o produto final (geralmente uma obra de arte), sendo assim, a documentação do percurso metodológico é preterida. Outra particularidade diz respeito ao meio de publicação e

\footnotetext{
${ }^{4}$ Concordamos que o distanciamento teórico é uma concepção "idealizada" (BORGDORFF, 2012, p. 37); todo estudo é conduzido por pelo menos um ser humano, logo, não existe "impessoalidade" na pesquisa acadêmica. 5 Termo em inglês: "embodied knowledge".
} 
Rev. Interd. em Cult. e Soc. (RICS), São Luís, v. 7, n. 1, p. 28- 43, jan./jun. 2021 ISSN eletrônico: 2447-6498

divulgação do estudo, no qual a redação textual pode não ser suficiente; faz-se necessário diversificar o tipo de suporte mediante o uso de registros em multimídia. Logo, as bases de dados que hospedam este tipo particular de pesquisa artística precisam oferecer tais recursos, uma vez que os mesmos são parte constante do estudo, e não apenas apêndices ou anexos. Os produtos finais destas pesquisas, além de abrirem para possibilidades diversas (apresentações artísticas, exposições de arte, páginas da internet, podcasts, videoaulas, intercâmbios artísticos, entre outros), podem fazer uso dos tipos característicos da pesquisa científica (teses, dissertações, artigos, etc.), caso os mesmos possam ser adaptados às necessidades que se apresentarem.

Nesta conceituação de pesquisa artística, está inclusa toda a literatura sobre práticas e produções artístico-culturais de quaisquer áreas do conhecimento. É fundamental ressaltar que a arte e a cultura - em minúsculas por constituírem objetos de estudo -, não são tópicos exclusivos de pesquisa das Artes - em maiúscula por se tratar de uma área acadêmica.

\section{ILUSTRANDO ALGUNS CONCEITOS}

Oferecemos adiante exemplos de situações em que as características da pesquisa artística, em sua vertente "através das artes", viabilizam a realização de estudos que não poderiam ser feitos apenas com o uso de métodos científicos estabelecidos na academia. Ao mesmo tempo, pretendemos oferecer ideias de como a metodologia artística pode contribuir para outros campos do conhecimento além das Artes.

4.1 O conhecimento não se limita somente a informações verbalizáveis - é esta, talvez, a característica de maior distinção entre Arte e Ciência, pois a primeira se relaciona mais diretamente a experiências que o ser humano vivencia. Torna-se fundamental, então, ampliar o que se entende por "conhecimento". Segundo Zamboni:

É comum se ter a ciência como um veículo de conhecimento, já a arte é normalmente descrita de maneira diferente, não é habitual pensá-la como expressão ou transmissão do conhecimento humano. Não obstante, é necessário entender que a arte não só é conhecimento por si só, mas também pode constituir-se num importante veículo para outros tipos de conhecimento humano, já que extraímos dela uma compreensão da experiência humana e dos seus valores. Tanto a arte como a ciência acabam sempre por assumir um certo caráter didático na nossa compreensão de mundo, embora o façam de modo diverso: a arte não contradiz a ciência, todavia nos faz entender certos aspectos que a ciência não consegue fazer. (ZAMBONI, 2001, p. 20) 
Rev. Interd. em Cult. e Soc. (RICS), São Luís, v. 7, n. 1, p. 28- 43, jan./jun. 2021

ISSN eletrônico: 2447-6498

Dessa forma, a compreensão de conhecimento se amplia para os outros tipos de informação provenientes do mecanismo sensorial de nosso corpo: tato, espacialização, cinestesia (que, em conjunto, compõem movimento, gesto e expressão corporal), olfato, paladar e um uso mais abrangente da visão e audição. O musicólogo português Jorge Salgado Correia reitera que ainda não possuímos tecnologia capaz de documentar todos estes tipos de informação, sendo esta a "fratura epistemológica" percebida na condução de pesquisas artísticas que precisam do acesso estes tipos de saberes, mas que são inviabilizados se houver um uso restrito dos métodos científicos convencionais:

[...] a linguagem gestual é contínua enquanto que a linguagem verbal é descontínua. A linguagem verbal deixa brechas, que não podem ser fechadas com palavras, apesar da quantidade de palavras a que se recorra para dar conta de cada detalhe. (CORREIA, 2016, p. 187)

Tal fato torna evidente, por exemplo, a efetividade do uso de metáforas da linguagem verbal para tratar de arte, pois esta é uma forma de acesso não apenas ao conhecimento no sentido de informações sensoriais, mas a experiências vivenciadas. O musicólogo Ricieri Zorzal oferece uma possível ilustração em um contexto de ensino e aprendizagem musical:

A linguagem figurada pode ser considerada como uma estratégia verbal de ensino que utiliza imagens, metáforas, analogias ou outras figuras de linguagem para criar uma relação entre algo que é próprio do universo musical com algo que, num olhar descontextualizado, parece descabido ao universo do instrumento tocado pelo aluno. Essa relação pode ser altamente subjetiva (e.g. 'pense no fluxo desta música como um rio de águas calmas'), situada entre a imaginação pura e o pensamento lógico (e.g. 'imagine um violinista executando essa frase'), ou mesmo uma comparação direta e pontual (e.g. 'sua mão deve atuar no formato de uma concha'). (ZORZAL, 2020, p. 4)

Esta particularidade, à qual nos referimos como conhecimento artístico, à próxima:

4.2 O conhecimento artístico é essencialmente oral e se mantém entre gerações - além da mencionada "fratura epistemológica" (CORREIA, 2016) que inviabiliza a possibilidade de uma "documentação artística" efetiva, a Arte assume a oralidade de uma forma que a Ciência tradicionalmente refuta. Mesmo com o avanço de abordagens mais recentes das Ciências Sociais e Humanas acerca da tradição oral, ela ainda é fortemente refém da documentação. Neste processo, os diversos tipos de informações e as experiências acabam por não se manter devido às ditas limitações da linguagem verbal. Cabe, então, refletir sobre o conceito de 
Rev. Interd. em Cult. e Soc. (RICS), São Luís, v. 7, n. 1, p. 28- 43, jan./jun. 2021 ISSN eletrônico: 2447-6498

documento. Nas áreas que compõem as Ciências da Informação segundo Tanus et al. (2012), a Biblioteconomia se ocupa do conteúdo/assunto do documento; a Arquivologia trata de sua autenticidade/função administrativa; e a Museologia analisa suas características estéticas e contextuais. Em todos os casos, o documento só mantém as informações se formos capazes de continuar abstraindo dele significados. Logo, o conhecimento só existe porque o ser humano está vivo ${ }^{6}$, mantém suas práticas culturais e associa suas experiências àquele objeto, que poderia ser tanto um documento quanto uma obra de arte. Dessa maneira, a informação, mesmo materializada em um documento sob qualquer tipo de suporte, mantém seu sentido graças ao registro imaterial que permanece entre gerações. $\mathrm{O}$ exemplo mais evidente disso é a Pedra de Roseta, que permitiu a compreensão dos hieróglifos egípcios a partir de sua comparação com a escrita em grego antigo presente na mesma, sendo esta a única convenção cultural que permanecia viva até o contexto da tradução, feita no primeiro quartel do século XIX (PEREIRA, 2020). No sentido oposto, temos a Geologia Histórica, que faz uso de depósitos sedimentares na busca por informações sobre a atmosfera antiga e a configuração anterior dos continentes, ou seja: as rochas se tornam um documento quando o ser humano assim passa a interpretá-las. E a ilustração mais evidente ocorre com as partituras: caso as convenções culturais da sonoridade dos estilos e gêneros musicais, a construção de instrumentos musicais, as técnicas de interpretação instrumental e vocal se percam em algum momento da história, elas perderão o sentido de registro documental, pois seus símbolos remetem a experiências sonoras estabelecidas entre gerações de musicistas e ouvintes.

Esta perspectiva imaterial do conhecimento artístico leva à seguinte característica:

4.3 Todo artista é um mestre da cultura popular, e vice-versa - um dos principais debates da Antropologia na atualidade é a questão da ancestralidade dos saberes em tradições culturais não-“Ocidentais”, especialmente no que concerne à perpetuação dos mesmos. Nesse sentido, a pesquisa artística pode oferecer uma valiosa contribuição, pois a dita ancestralidade é similar ao que nas Artes chamamos de "genealogia" do conhecimento, ou seja: a trajetória dos saberes entre gerações de mestres e aprendizes. A diferença entre estes dois conceitos é definida pela mesma convenção que diferencia a Sociologia da Antropologia. Ao trazer uma nova perspectiva do que se entende por "conhecimento" e "documentação", a pesquisa artística provê métodos capazes de assegurar a manutenção de produções e práticas artísticoculturais, tornando-se interessante a estudos antropológicos que assumirem a missão de zelar

\footnotetext{
${ }^{6}$ Aqui, remetemos à célebre afirmação de Descartes: "Penso, logo existo".
} 
Rev. Interd. em Cult. e Soc. (RICS), São Luís, v. 7, n. 1, p. 28- 43, jan./jun. 2021

ISSN eletrônico: 2447-6498

pela permanência de culturas variadas.

Destacamos, ainda, que a união entre as qualificações próprias do conhecimento artístico e sua manutenção através da oralidade se relacionam diretamente ao conceito-chave que diversos estudiosos da pesquisa artística têm chamado de "conhecimento incorporado", "conhecimento tácito" ou "conhecimento em ação" (BORGDORFF, 2012; HANNULA et al., 2014; LILJA, 2015). Ele nos leva à próxima característica da pesquisa através das artes:

4.4 Não há separação entre teoria e prática - partindo do fato que o artista faz parte de uma tradição de saberes estabelecida durante gerações; que grande parte deste conhecimento não é verbalizável; e que, segundo a Neurociência, o cérebro armazena os diversos tipos de informação por meio de associações (SPRENGER, 1999); os aspectos teórico-conceituais acabam se fundindo com sua própria realização prática. O pianista José Alberto Kaplan, ao abordar os fundamentos da técnica pianista, assume que tocar um instrumento musical é um fenômeno de origem psicológica, no qual o movimento corporal seria apenas a externalização de um processo que tem origem no cérebro (KAPLAN, 1987). Tais movimentos são fruto de anos de prática cujo aprimoramento exigiu inúmeros ciclos de memorização e esquecimento. Um simples gesto corporal traz consigo toda esta experiência, seja ao tocar um instrumento musical, realizar um movimento de dança, fazer uma atuação cênica ou coordenar as mãos para pintar um quadro. A simplicidade aparente deste processo, aliada à incompreensão de que informações não-verbais também são formas de conhecimento, levam à suposição na qual as ações dos artistas seriam baseadas apenas em "subjetividade" e no "senso comum", em um sentido depreciativo. Borgdorff acrescenta:

Teoria da ação, fenomenologia e filosofia da ciência nos ensinaram que toda prática e ação humana estão fundidas com teoria. Nesse sentido, a prática inocente não existe. Todas as práticas incorporam conceitos, teorias e compreensões. Práticas artísticas também, de maneira literal - não existem práticas e materiais nas artes que não estejam saturadas de experiências, histórias ou pensamentos. Não há material sem intervenção, e esta é uma das razões na qual a arte é sempre reflexiva. (BORGDORFF, 2012, p. 21)

Como objeto de estudo, é possível admitir uma separação teórica quando se trata do uso de métodos científicos convencionais. No entanto, ao retornar tais informações para o contexto artístico-cultural, elas precisam se fundir novamente à prática. Aqui, ressaltamos a diferença entre "aprender" e "apreender": o primeiro trata de um conhecimento a ser memorizado para algum fim imediato ou momentâneo, sem conexões diretas com outros 
Rev. Interd. em Cult. e Soc. (RICS), São Luís, v. 7, n. 1, p. 28- 43, jan./jun. 2021 ISSN eletrônico: 2447-6498

saberes - tem-se como exemplo a "decoreba"; já o segundo, denota um processo mais profundo no qual o conhecimento é apropriado de fato aos saberes e experiências, sendo incorporado e tomado para si. Esta última concepção é análoga ao que os artistas chamam de "amadurecimento" no ensino de uma habilidade qualquer.

4.5 A intuição está presente na pesquisa - refutada pelas convenções tradicionais do método científico, a pesquisa artística assume a intuição como sendo um potencial modo de cognição do ser humano, em similitude à razão (ou pensamento lógico-racional). Ela está presente em nossas tomadas de decisão cotidianas, caracterizando-se por ter como referência não a exposição racional de conceitos, mas nossas experiências de vida. E, por isso mesmo, a intuição se molda em convenções culturais como, por exemplo: ao fazer uma apresentação, o pianista precisa se adequar às características acústicas do ambiente; caso o espaço cultural tenha muita reverberação ("molhado", metaforicamente), ele utilizará menos o pedal direito (de sustentação do som), e na situação oposta (ambiente "seco"), ele terá liberdade para mais uso do mesmo. Essas tomadas de decisão não serão feitas com base no pensamento lógicoracional: o pianista irá simplesmente atentar para a sonoridade resultante e controlar o pedal instantaneamente, com base em sua imagem auditiva da obra e nas informações de sonoridade adquiridas ao longo de sua vida. Aqui, apresentamos o conceito de referência artística: similar às referências bibliográficas, ela recorre aos diversos tipos de informação que compõem o conhecimento artístico. Com base no caráter oral de manutenção deste último, a referência é frequentemente feita a indivíduos - muito mais do que a produtos resultantes de pesquisas acadêmicas. No campo da música popular, por exemplo, são recorrentes menções a musicistas como "referências", que são entendidas como influências de sonoridade, estilo de composição, interpretação e até de comportamento. E para findar esta breve discussão sobre a intuição na pesquisa acadêmica, ninguém menos que Albert Einstein:

Para mim, não há dúvida de que nosso pensamento funciona, geralmente, sem utilizar signos (palavras); é muito comum, aliás, que funcione de uma maneira consciente. Não é absolutamente necessário que um conceito seja ligado a um sigo reproduzível ou reconhecidos pelos sentidos, mas, quando isso acontece, o pensamento torna-se comunicável. (EINSTEIN In: MENECACCI, 1987, p. 100)

4.6 O processo pode ser mais relevante que o produto - na subárea que pode ser chamada de "Processos Criativos" e tem como objetivo a criação ou interpretação de uma produção artístico-cultural, o percurso metodológico desenvolvido para alcançar a meta proposta pode 
Rev. Interd. em Cult. e Soc. (RICS), São Luís, v. 7, n. 1, p. 28- 43, jan./jun. 2021

ISSN eletrônico: 2447-6498

ser mais útil à ampliação do conhecimento que o produto final em si. Para outros artistas, compreender o processo criativo é um aprendizado valioso, uma vez que a obra de arte é apenas a "ponta do iceberg" de todo o trabalho. É comum, ainda, o próprio meio acadêmico desconhecer a questão ao assumir que os esforços envolvidos em uma produção artísticocultural acontecem somente no ato da apresentação pública em si; seria como considerar que a comunicação oral de um artigo corresponde ao único momento do trabalho. Há também casos extremos, como o denunciado adiante:

[...] por que essa concepção de que professores e alunos de Música, Teatro, Artes Visuais e Dança têm de se apresentar gratuitamente, em 'nome da instituição' ou sob o fraco argumento da 'chance de visibilidade'? É imperativo que a universidade colabore para a afirmação das Artes como uma profissão, ao invés de repetir os mesmos problemas que o artista vivencia na sociedade. (CERQUEIRA, 2016, p. 176-177)

Ao adentrarmos na questão do artista na sociedade, é interessante estabelecer um paralelo com a visão de Lilja acerca do mercado de trabalho:

Em geral, mercados são conservadores e premiam objetos que representam normas ou valores estabelecidos. As forças do mercado raramente identificam produções artísticas experimentais ou inovadoras como positivas. (LILJA, 2015, p. 87)

Ela também tece um panorama sobre o meio acadêmico que aparenta ser semelhante ao das leis mercadológicas:

Tradições na ciência e na academia são fortes e foram desenvolvidas durante um longo período. Muito da vida acadêmica foi estabelecido em pedra sobre pedra, mas mesmo na ciência há processos de renovação e desenvolvimento em termos de formas de trabalho, apresentação e avaliação. (LILJA, 2015, p. 73)

Neste cenário, a pesquisa artística tem o potencial de promover inovações tanto no meio acadêmico quanto no mercado de trabalho. Para este último, a criação e inovação podem emergir de produções que questionam convenções estabelecidas, abrindo novos postos de atuação. No caso, o campo da Economia Criativa se mostra amplamente favorável, sendo possível propor projetos culturais com variados tipos de ações para difundir a produção, em diálogo com outros segmentos da cadeia produtiva do setor da Cultura - fato que também exige do artista sua inserção na Produção Cultural ${ }^{7}$.

\footnotetext{
${ }^{7}$ No Brasil, diversas instituições de ensino superior têm assumido a tarefa de fomentar produções e práticas artístico-culturais. Algumas iniciativas são: a) institucionalização de projetos culturais, assim como já ocorre
} 
Rev. Interd. em Cult. e Soc. (RICS), São Luís, v. 7, n. 1, p. 28- 43, jan./jun. 2021 ISSN eletrônico: 2447-6498

Ainda, sob um viés educacional, Lilja complementa que uma pesquisa artística de qualidade não gera, necessariamente, uma produção artística igualmente qualificada. Com o estudo do processo criativo, é possível aprender com as falhas resultantes de uma produção que deixou a desejar:

Arte de qualidade não é sinônimo de uma boa pesquisa artística. Uma boa pesquisa artística não é o mesmo que um produto artístico de qualidade. Através da pesquisa, nos aprimorarmos como artistas, o papel da arte é reforçado junto à sociedade e adquirimos ferramentas melhores para processos norteados pela qualidade. (LILJA, 2015, p. 87-88)

Dessa maneira, enfatizar o processo ao invés do produto faz com que a pesquisa artística tenha um potencial humanizador. A busca pela "perfeição" na produção artística, tal como vemos na exigência sobre músicos de orquestra e nas análises comparativas com as produções consagradas de convenções estabelecidas do cânone artístico, por exemplo, não nos permitem compreender que todos fazem arte e cultura dentro de suas possibilidades, cada qual em seu contexto. Assim, o estudo do processo propicia o entendimento de como os resultados artísticos foram alcançados naquela situação em particular.

\section{CONSIDERAÇÕES FINAIS}

Hannula et al., ao abordarem a perspectiva que o artista-pesquisador ou pesquisadorartista deve possuir, apresentam o dualismo "liberdade e responsabilidade": ele deve possuir livre arbítrio para as tomadas de decisão e assumir os riscos das mesmas, juntamente com a missão de lidar com as informações e utilizá-las na elaboração de quaisquer tipos de produtos artísticos ou culturais (HANNULA, 2014, p. 4). Como a pesquisa através das artes ainda se encontra em fase embrionária, é natural que não disponha de uma literatura consistente e métodos amplamente reconhecidos como respeitáveis. Portanto, é crucial que os acadêmicos em geral sejam compreensivos com esta situação, incentivando estas primeiras buscas - até porque todas as outras especialidades acadêmicas também atravessaram esse mesmo caminho em algum momento do passado.

Sobre a metodologia de pesquisa acadêmica na atualidade, apresentamos uma ilustração que insere a pesquisa artística neste contexto (Figura 2):

com os de pesquisa e extensão; b) fomento por meio de bolsas de iniciação artístico-cultural; e c) criação de unidades independentes de Cultura, como Conselhos de Cultura e uma Pró-Reitoria específica. 
Rev. Interd. em Cult. e Soc. (RICS), São Luís, v. 7, n. 1, p. 28- 43, jan./jun. 2021 ISSN eletrônico: 2447-6498

Figura 2. Situação da metodologia de pesquisa acadêmica

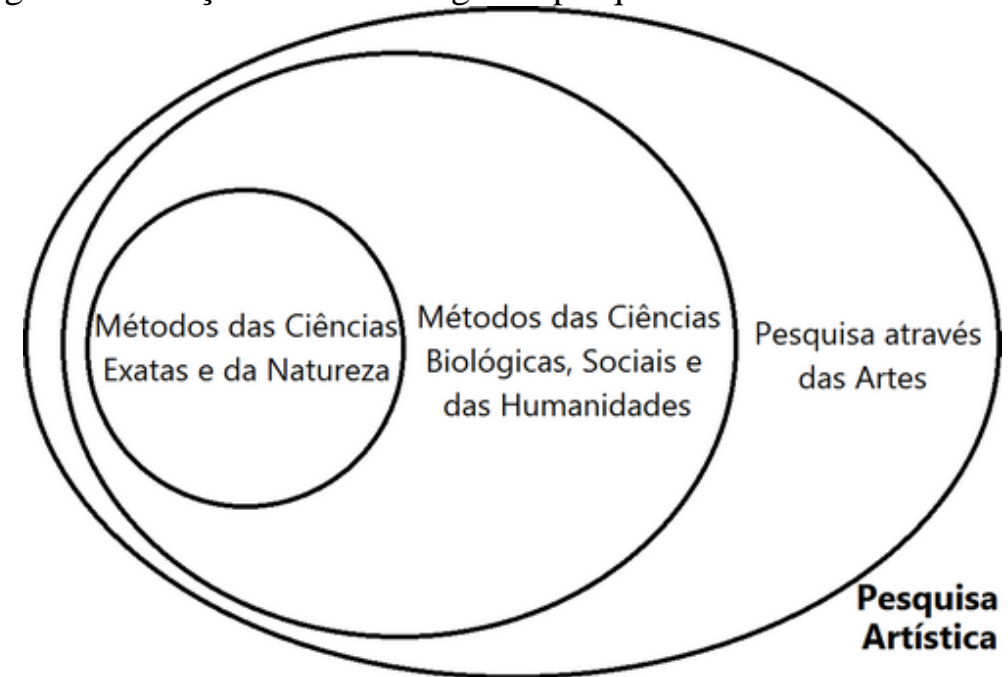

Fonte: Elaboração do autor em 2021.

Tem-se aqui uma representação clara de como os métodos de investigação estão distribuídos: as Ciências Exatas e da Natureza enfatizam o uso de métodos apropriados a seu próprio campo de ação; já as Ciências Biológicas ${ }^{8}$, Sociais e as Humanidades, além de fazer uso de métodos científicos característicos, importam recorrentemente aqueles adotados no campo anterior; por fim, a pesquisa artística faz uso de todos estes métodos, e agora se inclina para a elaboração de ferramentas metodológicas apropriadas ao desenvolvimento das Artes. Por ora, temos pressupostos e fundamentos elencados graças aos autores pioneiros do campo. No entanto, o caminho é longo e ainda precisamos desbravá-lo.

\section{REFERÊNCIAS}

BORGDORFF, H. The Conflict of the Faculties: perspectives on Artistic Research and Academia. Leiden: Leiden University Press, 2012.

BORGES, R. P. T. Repertório musicológico: conceituação e aplicações contemporâneas na pesquisa em música no Brasil. Tese (Doutorado em Música) - PPGM, UNIRIO, Rio de Janeiro, 2019.

BRUNER, J. S. O processo da educação. 3.ed. São Paulo: Nacional, 1973.

CERQUEIRA, D. L. O professor artista na universidade brasileira: questões e desafios. Música em Perspectiva, Curitiba, v. 9, n. 1, p. 165-185, 2016.

CORREIA, J. S. O efeito de ruptura dos termos 'corpo' e de 'qualidade' na investigação em

\footnotetext{
${ }^{8}$ Por desenvolver pesquisas que envolvem a saúde de seres humanos, as Ciências Biológicas precisam importar temas ligados à Ética e protocolos de investigação das Ciências Sociais e Humanidades.
} 
Rev. Interd. em Cult. e Soc. (RICS), São Luís, v. 7, n. 1, p. 28- 43, jan./jun. 2021 ISSN eletrônico: 2447-6498

performance musical. In: SIMPÓSIO DE ESTÉTICA E FILOSOFIA DA MÚSICA. 2016, Porto Alegre, Anais [...], Porto Alegre: UFRGS, v. 2, p. 186-188, 2016.

GARDNER, H. As estruturas da mente: a teoria das inteligências múltiplas. Porto Alegre: Artmed, 2002.

HANNULA, M.; SOURANTA, J.; VADÉN, T. Artistic Research Methodology: Narrative, Power and the Public. Nova York: Peter Lang, 2014.

KAPlAN, J. A. Teoria da Aprendizagem Pianística. 2. ed. Porto Alegre: Movimento, 1987.

KÖCHE, J. C. Fundamentos de metodologia científica: teoria da ciência e iniciação à pesquisa. 14. ed. Petrópolis: Vozes, 2011.

LILJA, E. Art, Research, Enpowerment: The Artist as Researcher. Estocolmo:

Regeringskansliet, 2015.

LÓPEZ-CANO, R.; SAN CRISTÓBAL OPAZO, U. Investigación artística en música: problemas, métodos, experiencias y modelos. Barcelona: Edição dos Autores, 2014.

MENECACCI, L. Conhecendo o cérebro. São Paulo: Nobel, 1987.

PEREIRA, L. Pedra de Rosetta. Disponível em: https://antigoegito.org/pedra-de-roseta. Acesso em: 21 jan. 2020.

SANTOS, B. S. Um discurso sobre as ciências. 5. ed. São Paulo: Cortez, 2008.

SPRENGER, M. Learning \& Memory: the brain in action. Alexandria: Association for Supervision and Curriculum Development, 1999.

TANUS, G. F. S. C.; RENAU, L. V.; ARAÚJO, C. A. A. O conceito de documento em arquivologia, biblioteconomia e museologia. Revista Brasileira de Biblioteconomia e Documentação, São Paulo, v. 8, n. 2, p. 158-174, 2012.

ZAMBONI, S. A pesquisa em arte: um paralelo entre arte e ciência. 2. ed. Campinas: Autores Associados, 2001.

ZORZAL, R. C. Estratégias para o ensino de instrumento musical: bases teóricas e exemplos práticos aplicados ao violão. Vórtex, Curitiba, v. 8, n. 3, p. 1-24, 2020. 